Cornelia Janik

\title{
Die Bindung internationaler Organisationen an internationale Menschenrechtsstandards
}

Eine rechtsquellentheoretische Untersuchung am Beispiel der Vereinten Nationen, der Weltbank und des Internationalen Währungsfonds

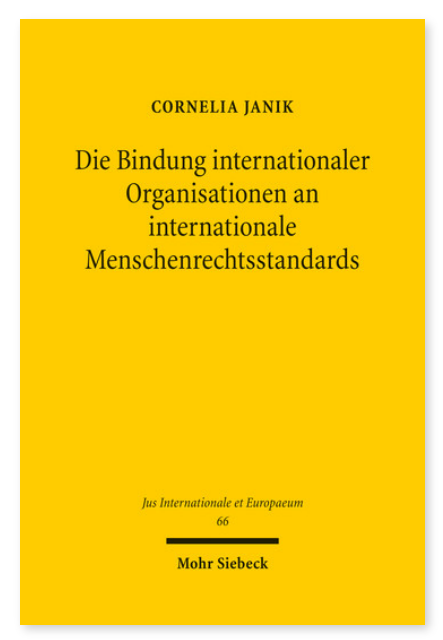

2012. XXI, 608 Seiten. JusIntEu 66

ISBN 978-3-16-152157-7

DOI 10.1628/978-3-16-152157-7

eBook PDF 129,00€

ISBN 978-3-16-151906-2

fadengeheftete Broschur 129,00€
Das internationale Menschenrechtsschutzsystem ist zunächst als Antwort auf Nationalsozialismus und Zweiten Weltkrieg entstanden und richtet sich an Staaten als potenzielle Menschenrechtsverletzer. Internationale Organisationen, allen voran die UNO, sind nach ihrer historischen Konzeption mit der Aufgabe betraut, Allgemeinwohl und Menschenrechte zu fördern. An Menschenrechtsverträge sind sie selbst nicht gebunden. Die Vorstellung, dass nur Staaten Menschenrechte verletzen, ist indes obsolet, wie etwa die black listing -Aktivitäten des UN-Sicherheitsrates oder die Finanzierung menschenrechtsadverser Projekte durch Weltbank und IWF vor Augen führen. Cornelia Janik zeigt daher methodische Ansätze auf, um die klassischen, auf Staaten zugeschnittenen Völkerrechtsquellen derart weiterzuentwickeln, dass sie auch internationale Organisationen zur Einhaltung internationaler Menschenrechte verpflichten.

Cornelia Janik Geboren 1980; Studium der Rechtswissenschaften in Frankfurt am Main; 2011 Promotion; Wissenschaftliche Mitarbeiterin am Lehrstuhl für Öffentliches Recht, Europarecht und Völkerrecht an der Goethe-Universität; Rechtsreferendarin in Frankfurt und Karlsruhe.
Jetzt bestellen:
https://mohrsiebeck.com/buch/die-bindung-internationaler-organisationen-an-internationale-menschenrechtsstandards-
$9783161521577 ?$ no_cache=1
order@mohrsiebeck.com
Telefon: +49 (0)7071-923-17
Telefax: +49 (0)7071-51104 